\title{
Time Series Forecasting Using ARIMA and ANN Models for Production of Pearl Millet (BAJRA) Crop of Karnataka, India
}

\author{
N. Vijay ${ }^{1^{*}}$ and G.C. Mishra ${ }^{2}$ \\ ${ }^{1}$ Central MugaEri Research and Training Institute, Jorhat, Assam, India \\ ${ }^{2}$ Institute of Agricultural Sciences, Banaras Hindu University, Varanasi, 221005, \\ Uttar Pradesh, India \\ *Corresponding author
}

A B S T R A C T

\section{Keywords}

ARMA, ANN, RMSE, Forecasting

Article Info

Accepted:

10 November 2018

Available Online:

10 December 2018
Time series prediction is a vital problem in many applications in nature science, agriculture, engineering and economics. The objective of the study is to examine the flexibility of artificial neural network model (ANN) in time series forecasting by comparing with classical time series ARIMA model. The data consist of area and production of Pearl millet (bajra) crop area ('000 ha) and production ('000 MT) from 1955-56 to 2014-15 were collected from "Agricultural Statistics at a Glance 2014-15, Karnataka, India were used in the study to demonstrate the effectiveness of the model. The experiment shows that ANN model outperform the ARIMA Models based on root mean (RMSE), MAPE and MSE.

\section{Introduction}

Pearl millet or Bajra (Pennisettum typhoides) are widely grown in Africa, Asia, China, and the Russian Federation and can be used as either grain or forage. Pearl millet is a highly drought-tolerant cereal crop and an important food grain.it is generally grown as a rainfed crop on marginal land with few inputs and little management. It is grown as a food crop in tropical Africa and India, with most of the production concentrated in Sahelian West Africa and north western India. These regions are characterized by high temperature, short growing season, frequent drought and sandy infertile soils. India is also considered to be the secondary center of origin for pearl millet, with many distinct cultivars growing throughout the country. In arid regions of India, pearl millet is a major source of food. These grasses produce small seeded grains and are often cultivated as cereals (Carl E pray and Latha, 2009). It is grown mostly in Rajasthan, Uttar Pradesh, Gujarat and Haryana, Madhya Pradesh Maharashtra, and Karnataka are the major Bajra producing states. (Directorate of Economics \& Statistics, DAC\&FW, 2014-15). In Karnataka It's cultivated an area of 0.234 million hectares ( $\mathrm{M} \mathrm{ha}$ ) with production of 0.248 million tons $(\mathrm{M} \mathrm{t})$ and an average productivity $1117 \mathrm{~kg} / \mathrm{ha}$. It's mainly cultivated in north eastern part of Karnataka namely 
Gulbarg, Bidar, Bellary, and Vijapur districts, respectively. (Directorate of Economics \& Statistics, Karnataka, 2014-15)Though they occupy relatively a lower position among feed crops they are quite important from the point of food security at regional and farm level. Statistical forecasting is used to provide assistance in decision making and planning the future more effectively and efficiently. Forecasting is a primary aspect of developing economy so that proper planning can be undertaken for sustainable growth of the country. Mainly there are two approaches of forecasting viz., (i) Prediction of present series based on behavior of past series over a period of time called as the extrapolation method, (ii) Estimation of future phenomenon by considering the factors which influence the future phenomenon, i.e., the explanatory method (Diebold and Lopez, 1996). Statistical forecasting is the likelihood approximation of an event taking place in future. (Box and Jenkins, 1970).Considering the above mentioned facts, a study was conducted to model and forecast the area and production of perarl millet (bajra) in Karnataka. Most commonly used classical linear time series models are ARIMA and linear regression models. Rathod et al., (2011), Naveena et al., (2014) used different time series models to forecast the coconut production of India. Khan et al., (2008) and Qureshi (2014) forecasted mango production of Pakistan using different statistical models. Omar et al., (2014) carried out price forecasting and spatial co-integration of banana in Bangladesh. Soares et al., (2014) compared different techniques for forecasting yield of banana plants. Olsen and Goodwin (2005) carried out a statistical survey on Oregon hazelnut production. Peiris et al., (2008) predicted coconut production in Sri Lanka using seasonal climate information. Mayer and Stephenson (2016) carried out statistical forecasting of Australian macadamia crop.

\section{Materials and Methods}

The yearly data of area and production of peral millet (bajra) crop area ('000 ha) and production ('000 MT) from 1955-56 to 201415 were collected from "Agricultural Statistics at a Glance 2014-15", report published by Department of Economics and Statistics, Government of Karnataka, Karnataka. In time series models pearl millet (bajra) crop, the data from 1955-56 to 2010-11 are used for model building and 2011-12 to 2014-15 are used for forecasting performance of the model and model validation. The statistical software $\mathrm{R}$ v.3.3 is used for modeling and forecasting pearl millet production time series of Karnataka. R v.3.3 software, package 'time series' was used for modeling and forecasting using ARIMA and package 'Forecast' was used for modeling and forecasting using ANN.

\section{Autoregressive Integrated Moving Average (ARIMA) Model}

ARIMA is one of the classical time series model of non-stationary time series analysis. ARIMA model allows to explain by its past, or lagged values and stochastic error terms. ARIMA modes are also called as mixed family of models. The pure models mean, the models which contain only AR or MA components, but not both. The term integration (I) is the reverse process of differencing, to produce the forecast. An ARIMA model is represented as ARIMA ( $p d$ q). An ARIMA model is expressed as follows;

$$
\begin{aligned}
& \emptyset(B)(1-B)^{d} Y_{t}=\theta(B) \varepsilon_{t} \quad \ldots \ldots \ldots \ldots . . .(3.3 .8) \\
& Y_{t}=\emptyset_{1} Y_{t-1}+\emptyset_{2} Y_{t-2}+\cdots+\emptyset_{p} Y_{t-p}+\varepsilon_{t}-\theta_{1} \varepsilon_{t-1}-\theta_{2} \varepsilon_{t-2}-\cdots-\theta_{q} \varepsilon_{t-q}
\end{aligned}
$$

$Y_{t i s}$ the time series, $\emptyset_{i \text { and }} \theta \mathrm{j}$ are model parameters, $\varepsilon_{t}$ is random error, $\mathrm{p}$ is number of autoregressive terms, $\mathrm{q}$ is number of moving 
terms and $\mathrm{B}$ is the backshift operator such that, $B Y_{t}=Y_{t-1}$ (Box and Jenkins 1970, Brockwell and Davis 1996).

The ARIMA model building consists of three stages, viz. identification, estimation and diagnostic checking. Parameters of this model are experimentally selected at the identification stage. Identification of $d$ is necessary to make a non-stationary time series to stationary. A statistical test can by employed to check the existence of stationarity, known as the test of the unit-root hypothesis. Popularly Augmented Dickey Fuller (ADF) test is utilized to test the stationarity. At the estimation stage, the parameters are estimated by employing iterative least square or maximum likelihood techniques. The efficacy of the selected model is then tested by diagnostic checking stage by employing Ljung-Box test. If the model is found to be insufficient, the three stages are repeated until satisfactory ARIMA model is selected for the time series under consideration.

\section{Artificial neural network (ANN)}

Artificial neural networks (ANNs) are nonlinear model that are able to capture various nonlinear structures present in the data set. ANN model specification does not require prior assumption of the data generating process, instead it is largely depend on characteristics of the data. The Artificial Neural Network (ANN) is a data driven, selfadaptive, nonlinear nonparametric statistical method. ANN functions similar to the human brains. They are the powerful tool for modelling, especially when the underlying data relationship is not known. Fundamental processing element of ANNs is a neuron. At the hidden layers, each neuron computes ${ }^{w_{i j}} \mathrm{a}$ weighted sum of its $\mathrm{p}$ input signals, ${ }^{x_{i}}$ for $\mathrm{i}=$ $0,1,2,3 \ldots, \mathrm{n}$ and then applies a nonlinear activation function to produce an output signal, Xi. The model of a neuron is shown in Fig. 1. A neuron $\mathrm{j}$ is described mathematically by the following pair of equations

$$
X_{j}=\sum y_{i} W_{i j}
$$

Where $y_{i t h e}$ activity is level of the jth unit in the previous layer and $W_{i j \text { is }}$ the weight of the connection between the ith and the jth unit.

Next, the unit calculates the activity $y_{j}$ using some function of the total weighted input. Generally, we use the logistic sigmoid function (Bilgili et al., 2007) and expressed as

$y_{i}=\left[1+e^{-x_{j}}\right]^{-1}$

The type of ANN used in this study is a feedforward multilayer perceptron (MLP) with back propagation (BP) learning algorithm, as commonly used in various complex environmental problems such as agriculture applications of MLP (Haykin, 1999). MLP with back propagation (BP) is a popular form of training multilayer neural networks learning algorithm, and it is widely used in solving various classification and prediction problems. Back propagation convergence is slow, but it has the advantages of accuracy and adaptability (Kisi, 2005).

It consists of three layers: an input layer, a hidden layer and an output layer. A set of neurons or nodes are arranged in each layer. The number of neurons in the input and output layers is defined depending on the number of input and output variables of the system under investigation, respectively. However, the number of neurons in the hidden layer(s) is usually determined via a trial-and-error procedure. As seen from the figure, the neurons of each layer are connected to the neurons of the next layer by weights. The typical performance function used for training feed-forward neural networks is the mean sum of squares (MSE) of the network errors: 


$$
M S E=\frac{\sum_{i=1}^{N}\left(Y_{i}-\widehat{Y_{i}}\right)^{2}}{N}
$$

Where, $Y_{\bar{i}}$ is the Actual value, $\hat{Y}_{\bar{i}}$ is the predicted value and $\mathrm{N}$ is the number of observation

\section{Results and Discussion}

As discussed earlier, the data set from 1955-56 to 2010-11 are used for model building and 2011-12 to 2014-15 were used for model validation. Performance of ARIMA and ANN model in both training and testing data set is given in tables 6 and 7, respectively.

\section{Fitting of ARIMA to bajra production of Karnataka}

The summary statistics of bajra production time series presented in table 1 explains that the series is highly heterogeneous as $\mathrm{CV}$ is high. ACF and PACF plots obtained in figure 2,shows that bajra production time series under consideration is non-stationary in nature, which is further verified by results of Augmented Dickey-Fuller (ADF) unit root test and Kwiatkowsk-Phillps-Schmidit-Shin unit root test (KPSS test)is given in table 2, which indicates the series is stationary at first difference which is confirmed by figure 3.Based on the maximum log-likelihood and lowest values of Akaike Information Criteria (AIC) and Bayesian Information Criteria (BIC) the candidate model (Table 3) i.e. ARIMA ( $\left.\begin{array}{lll}0 & 1 & 1\end{array}\right)$ was found adequate. After model identification, parameter estimation of the model was done using maximum likelihood estimation method. Parameter specification of ARIMA ( $\left(\begin{array}{lll}0 & 1 & 1\end{array}\right)$ model is given in table 4 finally, $\operatorname{ARIMA}(0,1,1)$ was found adequate for considered time series and parameter estimates of the same are given in Table 3. Auto correlation check for residuals obtained from ARIMA model of pearl millet (bajra) Production time series indicates the residuals found to be non-auto correlated as probability of chi-square is 0.8795 . Further, the model performance in training set and testing data set is given in Table 6 and 7 . Further observed versus fitted plot for bajra production time series in depicted in figure 4 .

\section{ANN model for modeling and forecasting} bajra Production of Karnataka

A multi-Layer Feed Forward Artificial Neural Network model was fitted to the data in 'forecast' package in $\mathrm{R}$ software. The Levenberg-Marquardt (LM) back propagation algorithm was used for ANN model building and based on repetitive iteration. Sigmoidal and linear activation functions were used as in hidden and output layers respectively. Ninety percent of the observations of data set are used as training data set for model building and rest of the observations were used as testing data set for model validation. Different numbers of neural network models with different model specifications are tried before arriving at the final skeleton of the model (Table 5).

Table.1 Summary statistics of bajra production time series

\begin{tabular}{|c|c|c|c|}
\hline Statistic & Bajra production & Statistic & Bajra production \\
\hline Observation & 60 & Minimum & 80 \\
\hline Mean & 210.86 & Maximum & 391.0 \\
\hline Median & 205.5 & Skewness & 0.239 \\
\hline Mode & $107.0^{\mathrm{a}}$ & Kurtosis & -0.937 \\
\hline Standard Deviation & 77.52 & Coefficient of Variation (\%) & 36.76 \\
\hline
\end{tabular}


Table.2 Stationary test of bajra production time series

\begin{tabular}{|c|c|c|c|c|}
\hline \multirow{2}{*}{ series } & \multicolumn{2}{|c|}{ ADF test statistic } & \multicolumn{2}{c|}{ KPSS test statistic } \\
\cline { 2 - 5 } & test Statistics & Probability values & test Statistics & Prob values \\
\hline Actual series & -2.69 & 0.29 & 0.925 & $<0.01$ \\
\hline First difference & -6.646 & $<0.01$ & 0.022 & $>0.1$ \\
\hline
\end{tabular}

Table.3 Log likelihood, AIC and BIC values of different ARIMA models for bajra production time series

\begin{tabular}{|c|c|c|c|}
\hline Models & Log-likelihood & AIC & BIC \\
\hline ARIMA(0,1,0) & -326.76 & 655.53 & 657.53 \\
\hline ARIMA(0,1,1) & -312.18 & $\mathbf{6 2 8 . 3 7}$ & $\mathbf{6 3 2 . 3 8}$ \\
\hline ARIMA(0,1,2) & -311.93 & 629.87 & 635.88 \\
\hline ARIMA(1,1,0) & -318.72 & 641.43 & 645.44 \\
\hline ARIMA(1,1,1) & -311.98 & 629.97 & 635.98 \\
\hline ARIMA(1,1,2) & -310.88 & 629.88 & 637.78 \\
\hline ARIMA(2,1,0) & -315.69 & 637.37 & 643.39 \\
\hline ARIMA(2,1,1) & -311.84 & 631.67 & 639.70 \\
\hline ARIMA(2,1,2) & -310.44 & 630.88 & 640.92 \\
\hline
\end{tabular}

Table.4 Parameter estimation of ARIMA ( $\left.\begin{array}{lll}0 & 1 & 1\end{array}\right)$ by maximum likelihood estimation method for bajra production time series

\begin{tabular}{|c|c|c|c|c|c|}
\hline Parameter & Estimate & $\begin{array}{c}\text { Standard } \\
\text { Error }\end{array}$ & t Value & Approx. Pr $>|\mathbf{t}|$ & Lag \\
\hline MU & 2.21 & 1.898 & 1.17 & 0.2431 & 0 \\
\hline MA1,1 & 0.81 & 0.082 & 9.89 & $<.0001$ & 1 \\
\hline
\end{tabular}

Table.5 Forecasting performance of ANN model for bajra production time series

\begin{tabular}{|c|c|c|c|}
\hline \multirow[t]{2}{*}{ Model } & \multirow[t]{2}{*}{ Parameters } & \multicolumn{2}{|c|}{ RMSE } \\
\hline & & Training & Testing \\
\hline $2: 2 S: 1 L$ & 9 & 59.45 & 55.00 \\
\hline $2: 4 \mathrm{~S}: 1 \mathrm{~L}$ & 17 & 57.25 & 39.38 \\
\hline 2:6S:1L & 25 & 66.93 & 55.04 \\
\hline 2:8S:1L & 33 & 79.65 & 62.56 \\
\hline $2: 10 S: 1 L$ & 41 & 66.54 & 85.93 \\
\hline $3: 2 S: 1 L$ & 11 & 59.07 & 52.82 \\
\hline 3:4S:1L & 21 & 64.93 & 51.10 \\
\hline $3: 6 S: 1 L$ & 31 & 73.29 & 44.79 \\
\hline 3:8S:1L & 41 & 86.25 & 46.01 \\
\hline 3:10S:1L & 51 & 71.91 & 56.42 \\
\hline
\end{tabular}


Table.6 Model performance of ARIMA and ANN model for bajra production time series in training data set

\begin{tabular}{|c|c|c|}
\hline Criteria & ARIMA & ANN \\
\hline MSE & 5168.10 & 3278.67 \\
\hline RMSE & 71.88 & $\mathbf{5 7 . 2 5}$ \\
\hline MAPE & 31.73 & 21 \\
\hline
\end{tabular}

Table.7 Forecasting performance of ARIMA model for bajra production time series in testing data set

\begin{tabular}{|c|c|c|c|}
\hline \multirow{2}{*}{ Year } & Actual & \multicolumn{2}{|c|}{ Forecast } \\
\cline { 2 - 4 } & & ARIMA & ANN \\
\hline $\mathbf{2 0 1 1}$ & 261 & 243.392 & 265.78 \\
\hline $\mathbf{2 0 1 2}$ & 285 & 245.608 & 222.82 \\
\hline $\mathbf{2 0 1 3}$ & 331 & 247.824 & 285.13 \\
\hline $\mathbf{2 0 1 4}$ & 250 & 250.04 & 235.50 \\
\hline Criteria & MSE & 2195.005 & 1550.87 \\
& RMSE & 46.85 & 39.38 \\
\hline & MAPE & 11.42 & 10.82 \\
\hline
\end{tabular}

Fig 1. Neural network structure

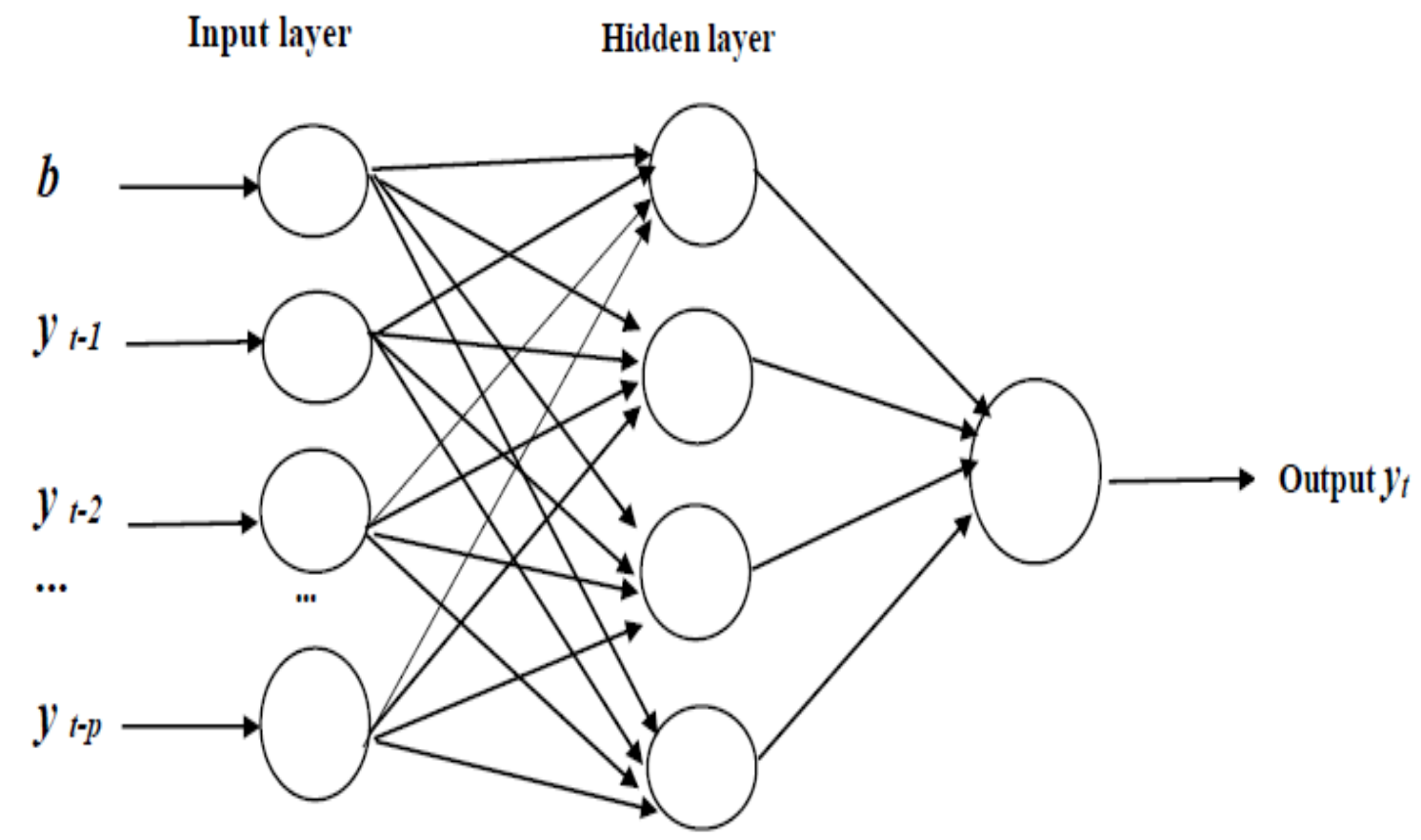


Fig.2 ACF and PACF plots for bajra production of original time series

Bajra Production

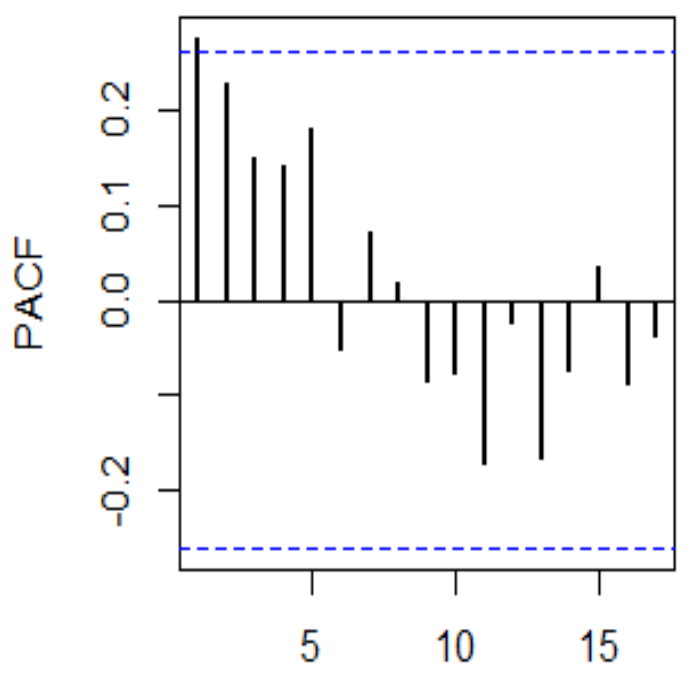

$\operatorname{Lag}$
Bajra Production

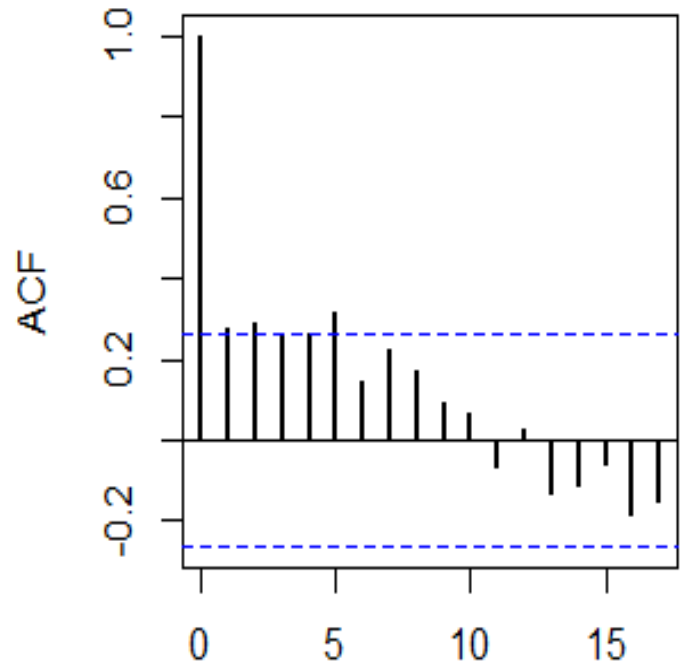

$\operatorname{Lag}$

Fig.3 ACF and PACF plots for first differenced bajra production (1) time series

Bajra Production

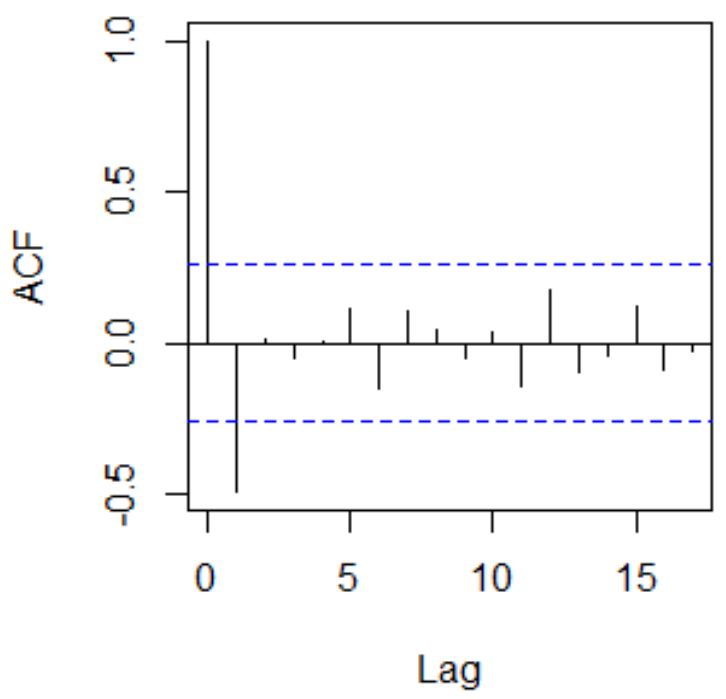

Bajra Production

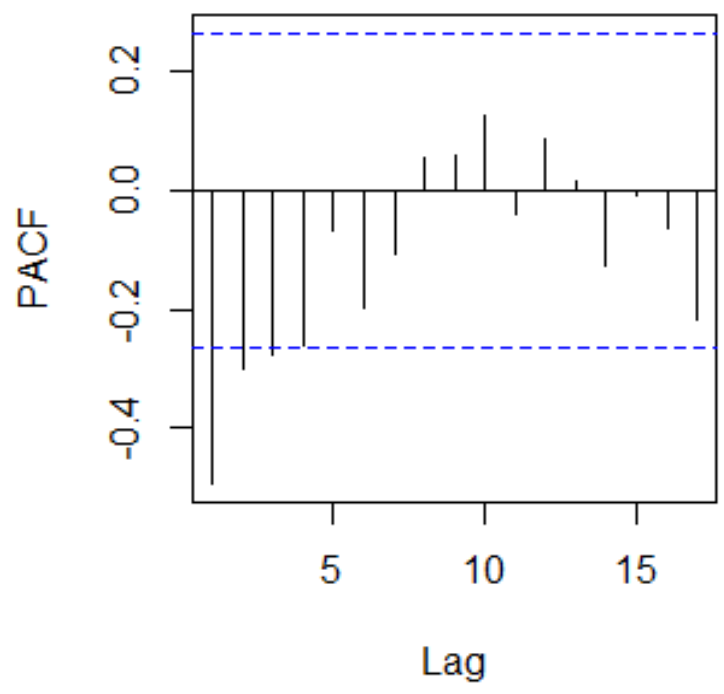


Fig.4 Actual v/s ARIMA fitted plot of bajra production time series

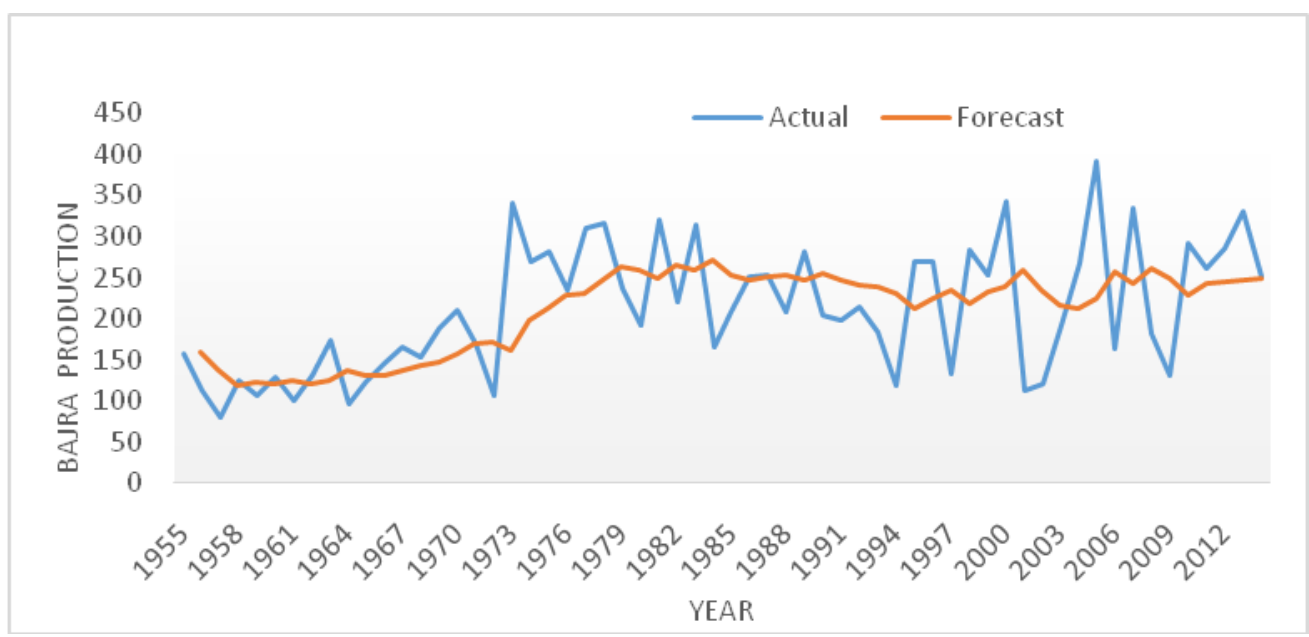

Fig.5 Actual v/s ANN fitted plot of bajra production time series

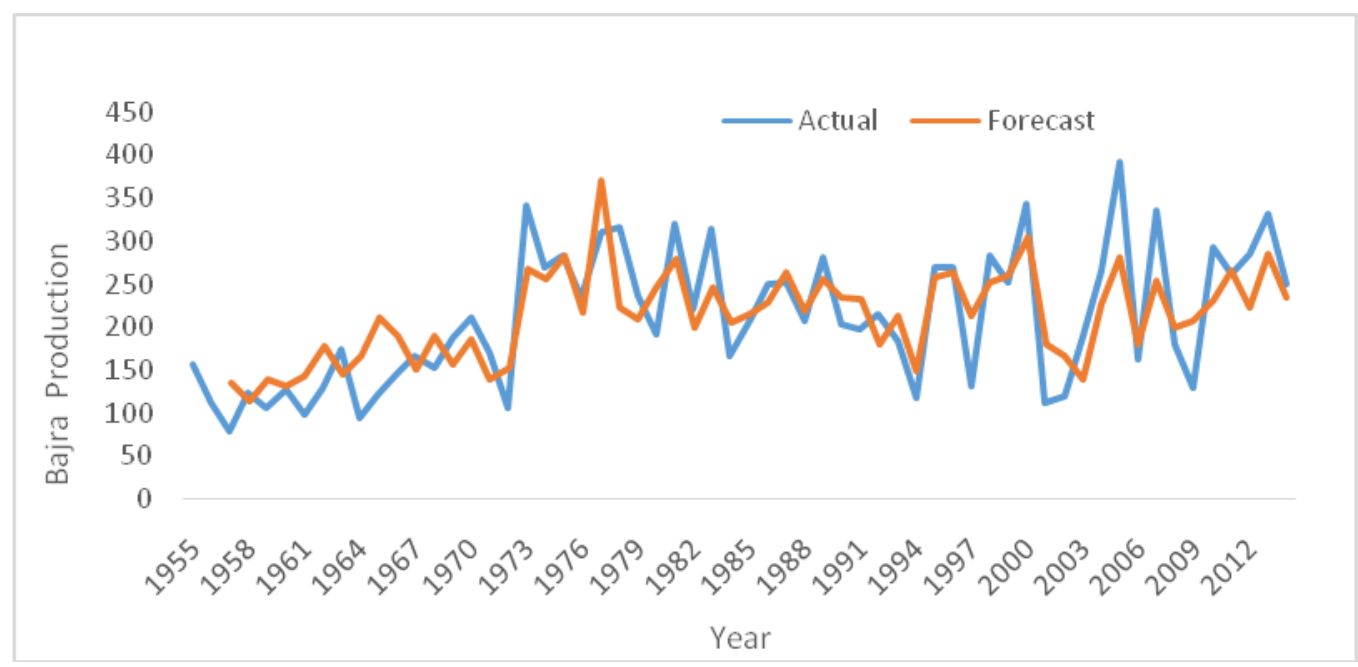

Forecasting performance of models under consideration

For comparison purpose, the training and the testing performance of ANN model were compared with ARIMA model. The ARIMA and ANN forecast are closely to actual values. It shows that both the approaches work well for the pearl millet (bajra) production of Karnataka data set used. The table 6 and 7 shows the comparison of training and testing precision among the two approaches based on RMSE, MAPE and MSE statistical measures.
Empirical results on pearl millet (bajra) production data set using two different models clearly reveal the efficiency of the ANN model.it shows ANN models are outperformed when compared to ARIMA model. The reason could be the nonlinear machine learning techniques can capture the heterogeneous trend in the data set and performed well as compare to ARIMA model.

On the basis of the results obtained in this work one can conclude that ARIMA models are not always adequate for the time series 
that contains non-linear structures. In this context, a nonlinear artificial intelligence technique like neural networks can be an effective way to improve forecasting performance. Based on the results obtained in this work one can infer that application of artificial intelligence techniques like time delay neural networks in modeling and forecasting of time series can increase the forecasting accuracy, in particular, the artificial neural network model performed better for forecasting pearl millet (bajra) production of India as compared to other models. This approach can be further extended by using some other machine learning techniques for varying autoregressive and moving average orders in other agricultural crops.

\section{References}

Agriculture Statistics at a Glance 2014-15. Directorate of Economics and Statistics, Department of Agriculture and Cooperation, Ministry of Agriculture, Govt. of India.

Agriculture Statistics at a Glance 2014-15. Directorate of Economics and Statistics, Department of Agriculture, Govt. of Karnataka

Bilgili, M., Sahin, B. andYasar, A.2007. Application of artificial neural networks for the wind speed prediction of target station using reference stations data. Renewable Energy, 32:2350-2360.

Box G.E.P. and Jenkins G. 1970. Time series analysis, Forecasting and control, Holden-Day, San Francisco, CA.

Brockwell, P.J. and Davis, R.A. 1996. Introduction to Time Series and Forecasting. Springer: New York.

Carl E.P. and Latha, N 2009. Pearl millet and sorghum improvement in India, IFPRI discussion papers 919, International Food Policy Research Institute (IFPRI).

Diebold, F.X. and Lopez, J.A. 1996. Forecast evaluation and combination: Handbook of Statistics, 14, Elsevier Science, Amsterdam.

Haykin, S. 1999. Neural Networks: A Comprehensive Foundation, New York.

Khan, M., Mustafa, K., Shah, M., Khan, N. and Khan, J. Z. 2008. Forecasting Mango Production in Pakistan an Econometric Model Approach. Sarhad J. Agri., 24(2): 363-370

Kisi, O.2005. Daily river flow forecasting using artificial neural networks and auto-regressive models. Turkish Journal Engineering Environment Sciences, 29:9-20.

Mayer, D. G. and Stephenson, R. A. 2016. Statistical Forecasting of the Australian Macadamia Crop. Acta Hortic., 1109: 265270. doi: 10.17660/ActaHortic. 2016.1109.43

Naveena, K., Rathod, S., Shukla, G. and Yogish, K. J. 2014. Forecasting of Coconut Production in India: A Suitable Time Series Model. Int. J. Agric. Eng., 7(1): 190-193.

Olsen, J. and Goodwin, J. 2005. The Methods and Results of the Oregon Agricultural Statistics Service: Annual Objective Yield Survey of Oregon Hazelnut Production. ActaHortic, 686: 533-537.

Omar, M. I., Dewan, M. F. and Hoq, M. S. 2014. Analysis of Price Forecasting and Spatial Co-Integration of Banana in Bangladesh, Eur. J. Business Manage. 6(7): 244-255

Peiris, T. S. G., Hansen, J. W. and Zubair, L. 2008. Use of Seasonal Climate Information to Predict Coconut Production in Sri Lanka. Int. J. Climatol., 28: 103-110. doi: 10.1002/joc. 1517 .

Qureshi, M. N. 2014. Modelling on Mango Production in Pakistan. Sci. Int., (Lahore), 26(3): 1227-1231.

Rathod, S. Surendra, H. S., Munirajappa, R. and Chandrashekar. H. 2011. Statistical 
Assessment on the Factor Influencing Agricultural Diversification in Different Districts of Karnataka. Environ. Ecol., 30 (3A): 790-794.

Soares, J. D. R., Pasqual, M., Lacerda, W. S.,
Silva, S. O. and Donato, S. L. R. 2014. Comparison of Techniques Used in the Prediction of Yield in Banana Plants. Scientia Hortic., 167: 84-90

\section{How to cite this article:}

Vijay, N. and Mishra, G.C. 2018. Time Series Forecasting Using ARIMA and ANN Models for Production of Pearl Millet (BAJRA) Crop of Karnataka, India. Int.J.Curr.Microbiol.App.Sci. 7(12): 880-889. doi: https://doi.org/10.20546/ijcmas.2018.712.110 